How coaching can play a key role in the development of nurse managers.

\title{
ABSTRACT
}

\section{Aims and objectives}

The aim of this study was to explore empirically the role that coaching plays in the development of nurse managers in order to inform further research and policy makers about the potential utility and value of this means of development.

\section{Background}

There is evidence of the importance of the role of nurse managers who are first line managers of a team of nurses within any health sector. However, there appears to be little understanding of the UK wide scope of nurse manager development across the United Kingdom (UK) and the means to increase its effectiveness. At the same time, it appears that some nurse managers receive coaching to help in their development.

\section{Design}

This is a mixed methods study, using a pragmatist paradigm.

\section{Methods}

Data was gathered from a quantitative survey and qualitative interviews. This paper is reporting the results of the qualitative interviews only. Twenty-one qualitative interviews were undertaken with nurse managers, coaches and directors of nursing to draw out their own experiences of coaching for nurse managers. Thematic analysis framework was used for data interrogation, identifying new patterns and emerging themes.

\section{Results}

Themes that emerged from interviews include how nurse managers were introduced to coaching, how they balanced transitions, the role of reflection, the value of relationships and overlaps between clinical supervision, mentoring and coaching.

\section{Conclusions}


Findings show that following coaching, nurse managers gained increased resilience, confidence and better coping mechanisms. This resulted in perceived improved team management and cohesion and appeared to lead to better quality of care for patients.

\section{Relevance to clinical practice}

This study suggests the importance of nurse managers accessing coaching, to enable transformational leadership of their teams of nurses. It suggests also the importance of organisations supporting a coaching culture, to ensure staff satisfaction, motivation and improved quality of patient care.

(word count 301)

\section{Key words:}

nurse manager, coaching, development of self, resilience, leadership, coaching culture, impact circle.

\section{Summary box}

'What does this paper contribute to the wider global clinical community?'

- The importance of coaching for nurse managers to improve their effectiveness and resilience in the role

- The value of using a coaching style of management for effective team management and cohesion

\section{INTRODUCTION}

The nurse manager role is a first line manager role undertaken by nurses who manage a team of nurses in any health sector. This role is found throughout the world wherever a group of nurses undertaking care require a more senior nurse to manage them. In the United Kingdom (UK), the team can be ward-based in an acute hospital in the National Health Service (NHS) or private sector, or based in the community. Given the variety of specific role titles, the term nurse manager will, in this paper, be used to refer to a nurse 
manager, nurse team manager, charge nurse, ward sister, ward manager or nurse team leader in the community.

Nurses in this role have responsibility for the quality of care undertaken by their staff (Currie 2013), including giving and supervising direct patient care, performance reviews, staff rotas, finance management, recruitment and measuring quality indicators. The challenges of being a nurse leader and manager in health care and the NHS are complex, enormous and stretch professional and personal reserves on a daily basis.

Given this, the development of nurse managers to undertake this role effectively is crucial if they are to function effectively (Middleton 2012, Willcocks 2012). Coaching has been suggested as a valuable asset in the development of leaders and managers (Institute for Employment Studies 2012). Nurse managers undertake a management role but also require leadership skills to be able to undertake the role effectively. The presence of coaching in a development programme for senior managers in the public sector has been found to be correlated with improvement of both management and leadership skills (Coates 2013).

Despite the variable development available for managers in the health care sector, some programmes do introduce managers to coaching. However, there appears to be little empirical research on the value of coaching to develop the nurse manager role with a particular research deficit from the perspective of the nurse managers themselves (Rivers et al. 2011, Law \& Aquilina 2013).

Although coaching has been shown to be of benefit to executive level managers in health care (McNally \& Cunningham 2010) there is still limited empirical evidence on its benefits to nurse managers. This paper will contribute to and build on the limited empirical evidence 
already produced in the area of coaching for nurse manager development. The initials NM will be used to denote nurse manager in this paper.

\section{BACKGROUND}

Some NMs may feel inadequately prepared for their line manager role and this hinders their ability to perform their roles effectively. The importance of some preparation prior to a manager being appointed has been identified (Duffin 2012), so they can be better prepared to succeed in their new role. If this pre-preparation is in place it is suggested that managers can then better contextualise the learning they undertake once in post (Duffin 2012).

For NMs, however, lack of adequate preparation has persisted. Many NMs feel very inadequately prepared when they take on the role, then confused and unsupported in their development once in the role (Sawbridge \& Hewison 2011). The importance of staff development and a distributed leadership model to empower clinical leaders, have been identified as key themes in what makes a top hospital by Robinson and Tyndale-Biscoe (2013). However, there is still no national programme for the development of NMs, although there are some programmes in place, such as those designed by the Royal College of Nursing (RCN), the professional union for nurses and midwives and the NHS Leadership Academy. The RCN's Clinical Leadership Programme provides a structure to develop the leadership and management skills and competence for NMs and is one of the longest running programmes of its type in the United Kingdom, having run since 2001 (RCN 2009).

However, not all NMs have access to these programmes due to lack of funding from their employer, lack of release time from work or simply that it has not been suggested to them as a method of development (McNally \& Cunningham 2010). In addition, many NHS Trusts have designed their own NMs' development programmes and these are run 'in house'. Although these programmes may contain a range of topics, such as 360 -degree feedback, 
aptitude testing, understanding finance, human resources training, management and leadership, mentoring and coaching etc. there is no national benchmark for them to ensure parity, quality and content.

Coaching is one of the key approaches through which leadership within organisations can be developed (Hawkins 2012, NHS Leadership Academy 2013). Effective coaching can be used by employers to retain key employees and helps to create a cohesive workforce, which will work effectively even when under pressure (Hawkins 2012, Field 2013). Coaching has undergone a major change and is now actively sought by employees rather than being seen as a remedial process for underperformance (Lane 2010, McNally \& Cunningham 2010). Coaching is also now seen as one of the most effective methods for managing talent and is seen as an opportunity for leaders to have insightful conversations and reflect on their performance (Joo, et al. 2012, The Chartered Institute of Personnel and Development 2013).

There are a variety of definitions of coaching. The definition from The Chartered Institute of Personnel and Development is that coaching is about 'developing a person's skills and knowledge so that their job performance improves [...] it lasts for a short (fixed) period and focuses on specific skills and goals' (The Chartered Institute of Personnel and Development 2013, p.3). The rationale behind coaching has also been described as developing greater understanding through discussion and reflective thought to enable any manager to become a more complete and authentic leader (Cox et al. 2010).

It has been suggested that for coaching to be effective it needs to be valued from the executive level right through to the clinical staff (McNally \& Cunningham 2010). Executives who have received coaching themselves are more likely in turn to use coaching successfully for their managers (Hawkins 2012). There is evidence to suggest that if coaching has been undertaken competently and effectively then the employee will improve their performance 
(McNally \& Cunningham 2010, Moen \& Federici 2012). Coaching is valuable in helping a person to maximise their potential and enhance their performance and can be used for teambuilding, management of change and staff development (Woodhead 2011).

\section{METHODS}

A mixed methods approach was used. For the purposes of this paper, the focus will be on the qualitative interviews that were undertaken. Interviews were undertaken alongside the quantitative survey and the results of the survey will be reported in a subsequent paper. A hybrid of the embedded design from Cresswell and Piano-Clark (2007) was chosen, similar to the partially mixed methods concurrent design with dominant status of Leech and Onwuegbuzie (2007). The two types of mixed methods approaches were reviewed and it was determined that the approach to be used in this study fitted very well with the concurrent travelled but dominant pathway. The interviews were seen as the dominant pathway in this study.

21 Interviews were undertaken over a 9-month period and lasted approximately 1 hour. 11 nurse managers were interviewed with 1 male and 10 female. In addition, 5 coaches and 5 directors of nursing, all female, were interviewed. The participants worked in England, Scotland and Wales. This study adhered to the three dimensions identified for ethics in research; procedural, ethics in practice and professional codes (Guillemin and Gillam, 2004, p.263). The professional code applied in this study, being a registered nurse governed by the Nursing and Midwifery Council Code of Conduct (2015), was to act with integrity and honesty. Additionally, this code has been applied in this research to all aspects of the data collection process. Within a health care context, there was also a responsibility should any safeguarding issues have been mentioned. From the procedural perspective, both the survey and interview components of the research were approved by Oxford Brookes University Research Ethics Committee. 
Thematic analysis was used to draw out themes common to all participants. Thematic analysis involves reviewing coded or summarised data and relating elements to produce categories that identify the conceptual differences in the data (Ritchie et al. 2013). Thematic analysis was undertaken with the following phases as suggested by Harper \& Thompson (2013); familiarity with the data, generation of initial codes, exploration of themes. reviewing themes, classifying and naming themes. Once the cross-cutting themes were identified, the interviews were re-analysed, using pattern coding, to identify how each group viewed these themes and what patterns had emerged. The use of pattern coding has been documented as a reliable method of analysis when using mixed methods data (Saldana 2012). Finally the production of the results occurred.

\section{RESULTS}

The results were clustered into three key themes; why coaching occurred, the experience of being coached and outcomes following coaching. Each area will be described in turn. All names used are pseudonyms.

\section{Why coaching occurred.}

Many NMs were introduced to coaching as part of a leadership programme and, until this experience, coaching had sometimes been viewed as a remedial rather than a role enhancing process.

If the Trust were going to develop a nurse manager course then coaching needs to be in that for starters. Because I think that's very beneficial for both ways, for them as individuals getting it in their new role, but also to be able to provide it to their staff in supporting them in the new role that they've taken on. NM - Jane.

The value of seeking coaching to help with difficult line management decisions and to demonstrate leadership was identified was identified by all individuals from each of the three groups. This was particularly noticeable in relation to how the NM develops line 
management skills and leadership and how NMs deal with difficult situations. A number of NMs and coaches said the reason they had sought coaching was either to deal with difficult staff that they managed, or for problems with their own line manager.

The need to develop resilience and self-efficacy in their role was also identified as a key reason to seek coaching.

Following coaching .. I have much more resilience. NM - Jo.

I don't think I would have been as resilient through organisational change without that coach relationship. I could not have got through because I would have said something or done something that might have been far more career limiting than what I did say or do. DN Beth.

A number of NMs reported feeling overwhelmed by the role whether new in post or having been in the role for a while. Significantly in the context of concern about resilience (see Discussion) some participants actively sought coaching to help them cope with stress, whilst others who had been offered coaching through a development programme found that it helped them to balance more healthily their work and home life. Another respondent stated; For some people it might be about balancing home and work life. Another thing is around not taking home the stresses from work, letting it affect what's happening at home and, you know, ways that they can, again, manage that and deal with that. Coach - Emma.

\section{The experience of being coached.}

One of the main areas that emerged from the data was the complexity and value of relationships between the NM, their line manager, their team and their work organisation. What appears to emerge is how the relationships that the NM has with their coach, mentor and clinical supervisor are intertwined with their effectiveness in their relationships with their line manager, team and organisation. 
I thought it was going to be similar to clinical supervision I suppose, because you hear the word coaching, but it was very decidedly different. NM - Julie.

The importance of values and standards comes across from a variety of NMs and coaches. In reflecting those values and standards, the NMs felt the need to have a coach who intrinsically had the same ethics and values as themselves, whilst recognising this needed to sit alongside the perceived need for an external outlook. Although this was not reflected in the need for the coach to be a health care professional or come from the same organisation. This enabled the NMs to relate to the coaches more effectively and helped cement the relationship. NM Val sums this up.

I have a very good personal and professional working relationship with my coach and we [...] have a lot of the same values and standards of how things should be. So yes, l've found it enormously beneficial. NM - Val.

The importance for the organisation of $\mathrm{NM} /$ coach shared values and ethics was also mentioned by DN Helen as a factor when choosing either a coaching company or internal coaches. The NMs in general set their own agenda when they received coaching and this occurred even when the organisation had recommended coaching to help with role development. The first session of coaching was influenced by the assessments undertaken on a development programme, such as a 360-degree evaluation etc., and the NMs reported usually being able to work on the areas they really wished to.

I would see coaching as the beginning of that process, to try and facilitate somebody finding the answers to a situation themselves. Because sometimes, [...] it may be the first time they've actually thought about it that way. NM - Lesley

It is hard, a hard transition. I do think you need to have somebody more experienced and with tools to actually help you sort of sift your way through it all, particularly if you didn't have a good manager. NM - Pauline 
The key factor the NMs recalled, in being able to divulge their concerns and worries, was the confidential nature of the coaching relationship. Some NMs reported that they would not have undertaken coaching if it had been with a person in a line management capacity with respect to their role. They expressed their concerns about their own discussions not being kept confidential in this type of relationship and how this may have put them off coaching if it was the only option offered. The experience sometimes led to participants feeling out of their comfort zone which was appreciated when the relationship was honest and confidential. All I can say, in my own experience, I found it more useful when it was someone who could stand right back and be completely out of the political situation within the Trust. Rather than someone, who was already, maybe had some sort of learned helplessness or was already constrained by things going on politically or strategically within the Trust. NM - Lesley.

\section{Outcomes following coaching.}

The perceived ability of the NM to gain expertise in leadership and management following coaching development was reported as leading to improved relationships with their team and colleagues.

That's why I think coaching works quite well, to use those skills to find out what your teams strengths and weaknesses are. NM - Julie

The NMs had reported that the suite of methods that they had learnt while receiving coaching and the challenging and reflective nature of coaching was highly transferable to new problems and allowed the NM to use their own initiative more fully.

No, it's lasted. It's definitely lasted. So there's a tool box of skills that they've given me, of try this, try that, try the other. So even just about how to prioritise, I have a priority system that I learnt from coaching. So I suppose it's gathering skills and then you can add other things to it. But I think it's, yes it's definitely stayed with me. NM - Julie 
I tend to use a coaching style with colleagues. And my own boss definitely has a strong coaching style in her management approach, which I respond to very well. NM - Chris.

NMs also reported the value of having coaching at different stages of their career, in particular, when new tools and skills were required for new projects or new roles.

coaching.., enabled me to come up with the ideas of how I would change management certain projects that we were doing at the time, or proactively manage certain situations that we dealt with. NM - Jane

The NMs also appeared to gain greater job satisfaction in their role following coaching which was supported by directors of nursing.

It's a valuable activity .. people will be happier and more satisfied, you know, with the work that they do. And we know that that's good for patients, so it becomes a virtual loop. So I think it is a really important thing. DN - Beth

\section{DISCUSSION}

\section{Why coaching occurred}

The NMs interviewed were very willing to take on and become expert at the management and leadership required for their role, viewing coaching as an integral part of this. The value of coaching was seen by many as being able to join the perceived differences between being able to be a caring nurse and a competent manager. Becoming a NM is a significant career transition, building on current skills and experience, with the acquisition and employment of new skills and competencies. Thus, it is important that coaching also helped to show that the skills required for each role are not incompatible. The new insight gained from the participants in this study was the value the NMs ascribed to having been introduced to coaching as part of a leadership programme. Many NMs would not have thought of accessing coaching had it not been part of a programme. Therefore, the investment in 
development, that includes a coaching component, seems to be a key route to enable NMs to access a support mechanism that many would not have considered.

The value of developing the NM to demonstrate leadership capability has been identified by The Kings Fund (2011). However, being able to demonstrate leadership is more difficult if the NM is unable to perform even basic management components of the role, such as financial and human resource management. This lack of effectiveness was expressed by NMs in terms of 'incompetent, failing, out of depth and didn't know what we didn't know'. All of these terms suggest that these are a group of staff who operate under immense amounts of pressure, often with little support for undertaking such a complex role. On top of this, they have a fear of failure (Sawbridge \& Hewison 2011), which is now exacerbated by the fallout from the Francis Enquiry (2013) and their own professional regulatory body requirements to undertake their role effectively.

In this study, coaching benefitted NMs undertaking a role that is complex and, at times, lonely, pressurised and vulnerable. The NMs emphasised the importance of coaching to either develop or enhance their resilience. Resilience, it is suggested, is interlinked with the values of the employee and those of the organisation. If these values were in alignment then resilience was increased (Lawton-Smith 2013). The development of resilience through coaching is also associated with the ability to face adversity more effectively and to improve self-efficacy (Baron\& Morin 2010). This study supports these prior findings in the context of NMs. The value of nurturing and developing the leadership skills of NMs to develop resilience in a complex health care world has been identified by Gooch (2012) and McDonald et al. (2013). The need for NMs to build resilience, so that they can manage this most complex and pressured of roles is, in addition, entwined with self-efficacy (Baron \& Moron 2010). The constructs of resilience and self-efficacy are interlinked, with the ability to realise self-efficacy being to some extent dependent on resilience. The ability to persist, in 
the face of challenges, is dependent on thinking positively and creating a positive environment. It can be argued that coaching can bring resilience to the NM role to enable them to manage this adversity more effectively (Jackson \& Daly 2011).

The supportive relationship gained by the NMs through coaching enabled them to reflect on both professional and personal issues. The study contributes to the evidence that coaching can relieve both anxiety and stress (Grant, et al. 2009). . In addition, the value of the support to set goals and work through issues was indicated by the participants in the study. The reflective components, plus the goals and working through issues, combined with a systematic engagement in coaching, was reported to lead to increased resilience in NMs and increased self-efficacy. Their increased resilience was connected with a perceived increase in self-confidence in their own ability, which in turn led to less stress. They were reported also to be more proactive in dealing with staffing issues and managing projects.

\section{The experience of being coached}

NMs used coaching to understand themselves better in relation to their role and to know how they appeared to others, which in turn helped NMs to realise their potential. It was important for the NM to be able to interpret their teams and their own line manager's behaviour styles so that the NM could adapt their management style to get the best out of a situation. Beyond the practical operational benefits of a learning, adaptive management style the importance of working effectively with a line manager is seen as essential for good working relationships and satisfaction in the role (Goldsmith et al. 2012). Coaching enabled the NM to define themselves in terms of their self, rather than just by the role they were undertaking. This insight led to more effective relationships with their team and prompted the NM to behave in a more transformational style. This is associated with empowerment of their staff and leads to higher quality and innovative practice and less staff turnover (Borrill et al. 2000). 
As well as developing resilience, the NM developed a healthier approach to coping, which is considered important for dealing with stress (McLeod 2010, Bakker et al. 2012). They used a problem focused approach to managing rather than an emotion focused approach, helping to shift their coping approach from being vulnerable to becoming resilient (McLeod 2010). This shift in coping is a significant factor in the NM being more effective in their role and supporting their team to be more effective.

Coaching can enhance skills, develop awareness in new leaders, maximise their motivation to perform well in their new role and help them develop their confidence and self-worth in a new testing environment (DeCampli, et al. 2010, Joo et al. 2012). Coaching is usually seen as a process that allows an increase in the coachee's self-awareness of their role and potential and what they can do to improve their performance (Moen \& Federici 2012). Significantly, NMs did not anticipate this development of self-awareness to be part of the caoching process before they undertook coaching, citing it as an additional unexpected benefit of the process.

Whilst some participants had sought coaching independently, others had received coaching via support from their employer. It was also reported by participants that some coaches were employees of their organisation, as opposed to a coach from outside the organisation. Organisational knowledge could be seen as either a help or a hindrance as far as the NMs were concerned. Some of them felt that institutional knowledge was useful so the coach knew in which context they were working. However, others felt that this may blinker the coach and they would prefer to be coached by someone who was a skilled coach and who was not tainted, as they saw it, by organisational knowledge.

\section{Outcomes following coaching}

The participants reported that they were able to improve patient services following coaching. As such, the findings from this research seem to concur with the findings from the evaluation 
undertaken by the Institute for Employment Studies (2012). The money spent on coaching enabled participants to either manage projects more effectively and/or deliver a service change that was more effective than expected. The participants directly attributed their ability to undertake these projects and changes to the coaching they received (Institute for Employment Studies 2012).

Participants reported that the improved management of staff appeared to lead to improvements in the quality of care given to patients, which was measured, for example, by improvements in patient satisfaction audits. Coaching reduces conflict because problems are identified quickly and managed in a more effective manner (McNally \& Cunningham 2010). The NM had more skill in identifying how to deal with a problem and more insight into how to manage different types of staff.

Using a coaching style of management made a difference to the way NMs felt as they were facilitating staff to work effectively, rather than being overly prescriptive. This effect also translated into better working with their line managers and to being sensitive to a line managers' working style. This is echoed by Clutterbuck (2012), where the importance of working effectively with your line manager is seen as essential for good working relationships and role satisfaction. The NMs reported enhanced self-awareness, ability to clarify personal strengths and enhanced professional and social skills, resonating with the study of Law and Aquilina (2013). They were more confident in their own decision-making ability and were able to use a range of tools to achieve this. This stemmed from them reclaiming their role and being in the driving seat with it, rather than the role driving them. This was driven by the balance between how much the NM felt they were in control of a situation and how much they were unable to control events around them.

\section{CONCLUSION}


There is a need for organisations to invest in the development of NMs. This has been exemplified by the media coverage concerning the need for good management and leadership in health care (Sawbridge and Hewison 2011; Francis 2013; Keogh 2013), in particular from NMs as the leaders of staff who deliver direct patient care. It is open to question, therefore, why at the very time when enhanced management and leadership skills are required of health care leaders, NMs are reporting lack of access to development programmes, including coaching. Enduring and increasing pressure on funding would seem to be the most likely reason, doubly concerning when even small amounts of coaching in turn can be shown to improve both efficacy and efficiency. While most NMs had been introduced to coaching through a development programme, it is important to note that coaching does not need to be accessed solely via that route. Investing in the future capabilities and skills of key staff characterises of many resilient and successful organisations, the investment not being limited to career transition specific development programmes.

NMs used coaching to understand themselves better in relation to their role and to know how they appeared to others, which helped NMs to realise their potential. Coaching enabled the NM to define themselves in terms of their self, rather than just by the role they were undertaking. This insight led to more effective relationships with their team and prompted the NM to behave in a more transformational style (Van Commenee 2013). The value to the NM of understanding the relationships they have with their staff cannot be underestimated.

The strong message is to have a coach who is not the NM's line manager or with direct line management links with the NM within their own organisation. This does not just relate to concerns about confidentiality but is compounded by the fact that some NMs need coaching to address the problems they have with their line manager.

In this study, coaching benefitted NMs undertaking a role that is complex and, at times, lonely, pressurised and vulnerable. The importance to either develop or enhance their 
resilience was valued by NMs. The supportive relationship gained by the NMs through coaching, enabled them to reflect on both professional and personal issues. The study contributes to the body of evidence that coaching can relieve both anxiety and stress. As well as developing resilience, the NM developed a healthier approach to coping, which is considered important for dealing with stress. They used a problem focused approach to managing rather than an emotion focused approach (McLeod, 2010; Lawton-Smith 2013) helping to shift their coping approach from being vulnerable to becoming resilient (McLeod 2010) . This shift in coping is a significant factor in the NM being more effective in their role and supporting their team to be more effective.

\section{RELEVANCE TO CLINICAL PRACTICE.}

The development of managers has been associated with many benefits including their own motivation and their team cohesion (Baron \& Morin 2010). It is crucial when enhanced management and leadership skills are required of health care leaders, that NMs are given access to development programmes, including coaching. While most NMs had been introduced to coaching through a development programme, it is important to note that coaching does not need to be accessed solely via that route. As NMs appear not to know the value of coaching until they have received it, they may not request it even if there is an opportunity. Therefore, in addition to coaching being widely supported by their employer, all NM developmental programmes would benefit from the introduction of coaching.

\section{REFERENCES}

Bakker, J., Holenderski, L., Kocielnik, R., Pechenizkiy, M. and Sidorova, N. (2012) Stess@Work: from measuring stress to its understanding, prediction and handling with personalized coaching. IHI'12. Proceedings of the 2nd ACM SIGHIT International Health Informatics Symposium. pp. 673-678. ACM New York, NY, USA

Baron, L. and Morin, L. ( 2010)The impact of executive coaching on self-efficacy related to management soft-skills. Leadership \& Organization Development Journal 31 (1), pp. 18-38 
Borrill, C. S., Carletta, J., Carter, A. J., Dawson, J. F., Garrod, S., Rees, A., Richards, A., Shapiro, D. and West, M. A. (2000) The Effectiveness of Health Care Teams in the National Health Service. Birmingham: Aston University.

The Chartered Institute of Personnel and Development (2013) Coaching and mentoring Available at: http://www.cipd.co.uk/hr-resources/factsheets/coaching-mentoring.aspx (Accessed: 27 January 2014).

Clutterbuck, D . (2012) Why Line manager coaching often doesn't work and what to do about it. Clutterbuck Associates.

Coates, D. (2013) 'Integrated Leadership Development Programmes: Are they Effective and What Role Does Coaching Play?', International Journal of Evidence Based Coaching and Mentoring Special Issue 7, June, pp. 39-54.

Cox, E., Bachkirova, T. and Clutterbuck, D. (2010) The Complete Handbook of Coaching. Thousand Oaks, CA: Sage Publications

Cresswell, J. W. and Plano Clarke, V. L. (2007) Designing and conducting mixed methods research. Thousand Oaks, CA: Sage Publications.

Currie, G. (2013) Patient safety: NHS middle managers can bridge gap between ward and board. Available at http://www.theguardian.com/healthcare-network/2013/nov/21/nhs-middlemanagement-information-sharing-ward-board (Accessed: 21 November 2013).

DeCampli, P., Kirby, K. K. and Baldwin, C. (2010) 'Beyond the classroom to coaching: preparing new nurse managers', Critical Care Nursing Quarterly, 33(2), pp. 132-7.

Duffin, C. (2012) 'Major study confirms link between nurse staff levels and care quality', Nursing Standard, 26(30), p. 7.

Field, L. (2013) Enhanced team performance through effective management coaching. Available at http://www.moneymarketing.co.uk/news-and-analysis/advisers/liz-fieldenhanced-team-performance-through-effective-management-coaching/2000139.article (Accessed: 19 September 2013).

Francis, R. (2013) Report of the Mid Staffordshire Foundation Trust Public Enquiry. Available at http://www.midstaffspublicinquiry.com/report (Accessed: 7 February 2014).

Goldsmith, M., Lyons, L. S. and McArthur, S. (2012) Coaching for Leadership. San Francisco: John Wiley and Sons.

Gooch, S. (2012) 'A strong lead', Nursing Standard, 26 (43), pp. 18-9.

Grant, A. M., Curtayne, L. and Burton, G. (2009) 'Executive Coaching enhances goal attainment, resilience and workplace well-being: a randomised controlled study', The Journal of Positive Psychology, 4(5), pp. 396-407.

Guillemin, M. and Gillam, L. (2004) 'Ethics, Reflexivity, and "Ethically Important Moments" in Research ', Qualitative Inquiry, April(10), pp. 261-80.

Harper, D. and Thompson, A. R. (2013) Qualitative Research Methods in Mental Health and Psychotherapy: A Guide for Students and Practitioners. Oxford: Wiley Blackwell. 
Hawkins , P. ( 2012) Creating a Coaching Culture. Maidenhead: Open University Press.

Institute for Employment Studies (2012) CCG and Top leaders coaching: Key findings from analysis of evaluation surveys. Brighton: Institute for Employment Studies.

Jackson, D. and Daly, J. (2011) 'All things to all people: Adversity and resilience in leadership'. Nurse Leader 9, ( 3) p. 21-22

Joo, B-K., Sushko, J. and McLean, G. N. (2012) 'Multiple faces of coaching: Manager-ascoach, Executive Coaching, and Formal Mentoring', Organization Development Journal 30(1), p. 19.

Keogh, B. (2013) Review into the quality of care and treatment provided by 14 hospital trusts in England: overview report. Available at http://www.nhs.uk/NHSEngland/bruce-keoghreview/Documents/outcomes/keogh-review-final-report.pdf (Accessed 21 August 2013).

The Kings Fund (2011) The future of leadership and management in the NHS. Report from the Kings Fund Commission on Leadership and Management in the NHS. ISBN: 9781 857176209

Lane, D. A. (2010) 'Coaching in the UK - an introduction to some key debates', Coaching: An International Journal of Theory, Research and Practice, 3(2), pp. 155-66.

Law, H. and Aquilina, R. (2013) 'Developing a healthcare leadership coaching model using action research and systems approaches - a case study: Implementing an executive coaching programme to support nurse managers in achieving organisational objectives in Malta', International Coaching Psychology Review 8(1), pp. 54-71.

Lawton-Smith, C. (2013) Resilience in Leaders: conceptualisation and changes brought about by coaching. Unpublished DCM Thesis, Oxford Brookes University.

Leech, N. L. and Onwuegbuzie, A. J. (2007) 'A typology of mixed methods research designs', Quality and Quantity 43, pp. 265-275.

McDonald, G., Jackson, D., Wilkes L., and Vickers M ( 2013) Personal resilience in nurses and midwives: Effects of a work-based educational intervention. Contemporary Nurse 45(1), pp.134-143.

McLeod, S. A. (2010) Stress Management - Problem Focused Coping with Stress Available at http://www.simplypsychology.org/problem-focused-coping.html (Accessed: 26 February 2014).middl

McNally, K. and Cunningham, L. (2010) The Nurse Executive's Coaching Manual. Indianapolis: Sigma Theta Tau International.

Middleton, J. (2012) 'Develop ward sister role to improve care' Available at http://www.nursingtimes.net/opinion/editors-comment/develop-ward-sister-role-to-improvecare/5052011.article (Accessed: 29 January 2014). 
Moen, F. and Federici, R. A. (2012) 'Perceived Leadership Self-Efficacy and Coach Competence: Assessing a Coaching-Based Leadership Self-Efficacy Scale', International Journal of Evidence Based Coaching and Mentoring 10(2), p. 1.

NHS Leadership Academy. (2013) Healthcare Leadership Model. London: NHS Leadership Academy.

Nursing and Midwifery Council (2015) The Code. Available at http://www.nmc.org.uk/globalassets/sitedocuments/nmc-publications/revised-new-nmccode.pdf (Accessed: 9 December 2015).

Ritchie, J., Lewis, J., McNaughton Nicholls, C. and Ormston, R. (2013) Qualitative Research Practice. London: Sage Publications Ltd.

Rivers, R., Pesata, V., Beasley, M. and Dietrich, M. (2011) 'Transformational Leadership: Creating A Prosperity-Planning Coaching Model for RN Retention', Nurse Leader 9(5), pp. 48-51.

Robinson, P. and Tyndale-Biscoe, J. (2013) What makes a top hospital? CHKS Report 6 Available at http://www.chks.co.uk/userfiles/files/CHKS_2011_WMATH_3_FIN_lo-res(1).pdf (Accessed 15 August 2014).

Royal College of Nursing (2009) Breaking down barriers, driving up standards: the role of the ward sister and charge nurse. London: Royal College of Nursing.

Saldana, J. (2012) The Coding Manual for Qualitative Researchers. London: Sage.

Sawbridge, Y. and Hewison, A. (2011). Time to care? Responding to concerns about poor nursing care. Policy Paper 12 - December 2011. University of Birmingham, Birmingham: Health Services Management Centre.

Van Commenee, C. (2013) Coach your team to success Available at http://www.nursingtimes.net/home/leadership-academy/coach-your-team-tosuccess/5055384.article\# (Accessed: 1 March 2013).

Willcocks, S. G. (2012) 'Exploring leadership effectiveness: nurses as clinical leaders in the NHS', Leadership in Health Services 25(1) pp. 8-19.

Woodhead, V. (2011) 'How does coaching help to support team working? A case study in the NHS', International Journal of Evidence Based Coaching and Mentoring Special Issue 5, June, pp. 102-19. 